\title{
Balance measured by head (and trunk) tracking and a force platform in chemically (PCB and TCE) exposed and referent subjects
}

\author{
Kaye H Kilburn, Raphael H Warshaw, Brad Hanscom
}

\begin{abstract}
To determine comparability of methods, postural sway was measured simultaneously with a force platform and a device that registers head (and trunk) movements (head tracking). The effects of age, sex, height, weight, shoe area, and grip strength on both measurements were examined in 162 subjects. To determine whether either method had advantages in detecting abnormal balance 46 reference subjects were compared with 116 people randomly selected from 500 residents whose well water was contaminated with polychlorinated biphenyls (PCBs) and trichloroethylene (TCE) from a metal casting plant. Speed, mean radius, and distance of sway were equally reproducible with both methods. Correlation coefficients were 0.672 with the eyes closed and 0.588 with the eyes open. The balance of those exposed to PCBs and TCE was significantly worse than that of unexposed subjects by both head tracking $(1.50+71 \mathrm{~cm} / \mathrm{s} v 1.27+0.36 \mathrm{~cm} / \mathrm{s} ; \mathrm{p}<$ $0.034)$ and the force platform $(4.93+1.56$ $\mathrm{N}$ (kg force) $v 4.29+1.14 \mathrm{~N} ; \mathrm{p}<0.013$ ) with the eyes closed and differences were also significant with the eyes open. Head tracking and the force platform produced equivalent results. Measurement by head tracking is recommended for field studies because the device is more portable and is less influenced by weight and height. Both methods showed impaired balance associated with years of exposure to PCBs and TCE.
\end{abstract}

(Occup Environ Med 1994;51:381-385)

University of

Southern California

School of Medicine, Environmental

Sciences Laboratory, 2025 Zonal Avenue, CSC 201, Los Angeles, California 90033, USA and Workers Disease

Detection Services

Inc, $112 \mathrm{~N}$ Harvard

Ave, Suite 258,

Claremont, California

91711, USA

K H Kilburn

R H Warshaw

B Hanscom

Correspondence to

Dr K H Kilburn

Accepted for publication

23 February 1994
The objectives of this study were firstly to compare balance by two methods, force platform and head tracking, simultaneously in normal subjects to see whether there were differences and secondly, to extend this comparison to chemically exposed subjects. Thus the design examined the issues of methodological compatibility and also sensitivity to environmental exposures to polychlorinated biphenyls (PCBs), their contaminants, and thermal transformation products manifested by dizziness, lightheadedness, and loss of balance. Subjects in this study had used water wells heavily contaminated with PCBs and solvents including trichloroethylene (TCE). Their complaints led to us testing their bal- ance compared with that of referent subjects from a nearby area with a force platform and a head tracking device simultaneously. Such exposures have been previously associated with neurological complaints such as peripheral sensory and motor nerve dysfunction, and impaired nerve conduction velocities. ${ }^{1-3}$

In 1851 Romberg had subjects stand with their feet together and arms folded for his balance test. ${ }^{4}$ Breaking stance in less than a minute defined failure, so the test was insensitive. Many investigators ${ }^{5-12}$ have described methods to quantify balance since Goldberg in $1943^{13}$ and Bormann and Jalavisto in $1953^{14}$ tracked head movements photographically. In the past decade force platforms have been accepted as a standard method but there has been no published comparison with head tracking. Some force platforms must be sunk into the floor ${ }^{15}$ and seem unsuited for field or office use whereas, by contrast, the head tracking apparatus is handy, lightweight, and portable. ${ }^{16}$ Before adopting this technique, we compared it with the force platform to answer several questions. Firstly, are head tracking and a force platform equivalent methods of measuring balance? Secondly, does the head move independently of the body axis? Thirdly, do the direction and velocity indices of balance or the influence of age, height, weight, and other independent variables differ in the two measurements?

\section{Methods}

A cohort comparison design was used with 62 women and 54 men in the exposed group and 27 women and 19 men as referents. The exposed participants were an age stratified random selection from over 500 symptomatic residents exposed to PCBs in hydraulic fluid traced to a metal casting plant in Colbert County, Alabama. They had lived within 2.4 $\mathrm{km}$ of this plant for at least four years between 1956 and 1981 and most of them lived there at the time of the study. The hydraulic fluid in the die casting machines was composed of ethylene glycol containing $15 \%$ to $20 \%$ PCBs. Up to 100000 gallons per year of PCBs had been used in these machines for 17 years. Multiple analyses of the residents' well water in the 1980 s showed PCBs up to $3500 \mathrm{ppm}$ and trichloroethylene (TCE) concentrations above the Environmental Protection Agency (EPA) action concentration of $5 \mathrm{ppb}$. Concentrations of these "test" chemicals differed by one to two orders of magnitude among various well water samples. ${ }^{17}$ 
The referents were from Russellville, Alabama (in Franklin County, $30 \mathrm{~km}$ distant) or surrounding towns that were selected to match the exposed residents for sex, age, and years of educational attainment (highest school grade attained). They were interviewed to ascertain their willingness to be tested, to insure matching by age and sex to the exposed group and absence of employment at the die casting plant, or of living within $8 \mathrm{~km}$ of it. Examiners were blinded to the exposure state of the subjects. All subjects gave their informed written consent to the protocol, which was approved by the University human subjects review committee. Questionnaires were self administered for occupational exposures including to neurotoxins, hours of general anaesthesia, and for past neurological and medical diseases. They were checked for completeness by trained interviewers.

Grip strength was measured in kg by compressing the calibrated spring of a dynamometer. Weight and height were measured in subjects without shoes by means of a clinical platform scale and extendable metal metric rod. Shoe area was measured by computerised planimetry.

Body balance was measured by both techniques simultaneously with the subject standing erect on the platform with feet together and arms folded, both with eyes open and with eyes closed, while wearing a sound emitting headband. For measurements with eyes open subjects focused on a target 6 feet away for 30 seconds. After a short rest period during which subjects were encouraged to relax and move they assumed the same position, focused on the target, and stood with eyes closed for 30 seconds. Three sequences of eyes open then eyes closed were separated by 30 to 45 seconds. Sway data were collected with a Neuro-Test, Inc Postural Sway Analyser with both force platform and positional tracking modules (NTI, Claremont, California, USA).

The force platform module is $8 \mathrm{~cm}$ high by $110 \mathrm{~cm}$ square with a $45 \mathrm{~cm}^{2}$ measurement area. Force is measured by eight foil deflection strain gauges placed two at each corner of the active area. The module was calibrated by placing a $20 \mathrm{~kg}$ load on each pair of strain gauges and adding increments of 1,4 , and 8 kg. A sampling rate of $4000 / \mathrm{s}$ was reduced by programming to $60 / \mathrm{s}$, which was 10 times faster than the expected frequency of sway. The reproducibility was within $2 \%$ of the greatest mass applied. The four unfiltered signals from each pair of gauges were integrated in the computer with software of our design. The head tracking module consists of two microphones mounted horizontally $36 \mathrm{~cm}$ apart on a tripod, which permits adjustment for the subject's height, and a sound emitter with a barely audible (4/s) click, which was secured by a headband behind the subject's ear. ${ }^{16}$ Its sampling rate was $16.67 / \mathrm{s}$; three times the expected frequency. The head tracking module was calibrated by moving the emitter along the boundaries of a 21.59 by $27.94 \mathrm{~cm}$ rectangle placed horizontally at the same height as a line connecting the midpoints of the microphones. The head tracking digitiser was connected directly without filtration to an IBM compatible computer. Repeatability was within $2 \%$. The force modules were connected to an IBM compatible computer with a controller for the position tracking module and an eight channel, 16 bit analog to digital converter. Force and position plots did not interact (bias each other) so they were displayed simultaneously in real time on a split screen and all coordinate pairs were recorded.

Results are reported for head tracking as mean radius of sway, eyes open (ro) and eyes closed (rc), and mean speed of sway eyes open (so) and eyes closed (sc). Mean radius was defined as the average distance from the centre point of all positions sampled during $60 \mathrm{sec}$ onds and could be regarded as the average deviation from this hypothetical centre. A small " $\mathrm{f}$ " in front of each value identifies the rate of change measured by the force platform data (fro, etc). Units of measurement are cm for radius and $\mathrm{cm} / \mathrm{s}$ for speed with head tracking and $\mathrm{kg}$ force or Newtons $(\mathrm{N})$ for the platform.

Comparison of head-trunk tracking measurements on 10 subjects tested while standing on a level floor and repeated while standing on the platform were not different, indicating that the size of the platform was sufficient to overcome possible confounding effects from the $8 \mathrm{~cm}$ height of the platform above the floor. This absence of effect makes field use of this platform practical where it would be difficult to level its top surface to the surrounding floor.

Distributions of mean radius of sway and of speed with eyes open and with eyes closed by head tracking and by the force platform were Gaussian. Of the eight transformations (to square, cube, square root, logarithm, 1/square root, inverse, 1 /square, and $1 /$ cube) only the inverse improved the untransformed (identity) data slightly for force. There were no improvements for head tracking in regression modelling. Differences were insignificant so we used untransformed data. Weight and height $\times$ weight were used to express body size.

All scores and computed data for sway were entered into a Tristar 486 computer and descriptive and analytical computations including $t$ tests and linear regression modelling used were carried out with Stata statistical software (Computing Resource Center, 10801 National Blvd, Los Angeles, California, 90064, USA, 1987). Differences with a $p$ value of $<0.05$ were considered statistically significant.

\section{Results}

The ages, educational level (last year of school completed), average high school grades, heights, and weights of exposed and referent men and women were similar (table 1). The exposed group had significantly higher family incomes for the past three years than did the 
Table 1 Descriptive data for exposed and referent groups

\begin{tabular}{|c|c|c|c|}
\hline & $\begin{array}{l}\text { Exposed } \\
(n=116) \\
\text { Mean }(S D)\end{array}$ & $\begin{array}{l}\text { Referent } \\
(n=46) \\
\text { Mean }(S D)\end{array}$ & $p$ Value \\
\hline $\begin{array}{l}\text { Age }(y): \\
\text { Women } \\
\text { Men } \\
\text { Overall } \\
\text { Education }(y) \\
\text { Grades }(A=1, F=5) \\
\text { Income }(\times \$ 1000)\end{array}$ & $\begin{array}{l}42 \cdot 7(12 \cdot 9) \\
39 \cdot 1(13 \cdot 5) \\
41 \cdot 1(13 \cdot 2) \\
12 \cdot 4(2 \cdot 3) \\
2.5(0 \cdot 6) \\
31 \cdot 18(23 \cdot 57)\end{array}$ & $\begin{array}{l}37 \cdot 0(16 \cdot 2) \\
41 \cdot 8(18 \cdot 0) \\
39 \cdot 0(16 \cdot 9) \\
12.5(2 \cdot 0) \\
2 \cdot 4(0 \cdot 6) \\
16.92(13 \cdot 30)\end{array}$ & $\begin{array}{l}\text { NS } \\
\text { NS } \\
\text { NS } \\
\text { NS } \\
\text { NS } \\
0.0003\end{array}$ \\
\hline $\begin{array}{l}\text { Alveolar alcohol }(\mu \mathrm{l} / \mathrm{dl}) \text { : } \\
\text { Women } \\
\text { Men }\end{array}$ & $\begin{array}{l}0.0001(0.0004) \\
0.0004(0.0008)\end{array}$ & $\begin{array}{l}0.0003(0.0006) \\
0.0001(0.0003)\end{array}$ & $\begin{array}{l}\text { NS } \\
\text { NS }\end{array}$ \\
\hline $\begin{array}{l}\text { Height }(\mathrm{cm}): \\
\text { Women } \\
\text { Men }\end{array}$ & $\begin{array}{l}161 \cdot 8(6 \cdot 2) \\
174 \cdot 7(6 \cdot 0)\end{array}$ & $\begin{array}{l}163.6(4 \cdot 5) \\
173.7(7 \cdot 2)\end{array}$ & $\begin{array}{l}\text { NS } \\
\text { NS }\end{array}$ \\
\hline $\begin{array}{l}\text { Weight (kg): } \\
\text { Women } \\
\text { Men }\end{array}$ & $\begin{array}{l}79 \cdot 7(18 \cdot 0) \\
87 \cdot 7(16 \cdot 7)\end{array}$ & $\begin{array}{l}74 \cdot 2(16 \cdot 0) \\
85 \cdot 3(19 \cdot 5)\end{array}$ & $\begin{array}{l}\text { NS } \\
\text { NS }\end{array}$ \\
\hline $\begin{array}{l}\text { Grip strength (kg); wome } \\
\text { Right } \\
\text { Left }\end{array}$ & $\begin{array}{l}30 \cdot 1(8 \cdot 8) \\
28 \cdot 0(7 \cdot 6)\end{array}$ & $\begin{array}{l}34 \cdot 7(6 \cdot 1) \\
33 \cdot 7(6 \cdot 1)\end{array}$ & $\begin{array}{l}0.015 \\
0.0007\end{array}$ \\
\hline $\begin{array}{l}\text { Grip strength (kg); men: } \\
\text { Right } \\
\text { Left }\end{array}$ & $\begin{array}{l}56 \cdot 1(13.3) \\
55.4(11.9)\end{array}$ & $\begin{array}{l}53.5(14 \cdot 1) \\
50 \cdot 1(14 \cdot 5)\end{array}$ & $\begin{array}{l}\text { NS } \\
\text { NS }\end{array}$ \\
\hline
\end{tabular}

$\mathrm{p}$ Values by $t$ test (two sided).

referents, which reflects an urban and rural difference. Income had no statistically significant coefficients separate from age and educational level in regression models. No subject in either group had an alveolar air alcohol concentration above $0.03 \mu \mathrm{l} / \mathrm{dl}$.

Occupational exposure to 15 known or potentially neurotoxic chemicals had occurred in $83 \%$ of the referent group, more than the $69 \%$ in the exposed group obtained by questionnaire. ${ }^{17}$ Subjects who shared exposure to single neurotoxicants made groups that were too small for separate analysis. Taken together they accounted for most of the cases, so they could not be eliminated from analysis. Because a greater proportion of the referent group had these exposures than did the exposed group, however, the overall effect would narrow the group differences. ${ }^{17}$

Sex was not a determinant of sway speed or radius in regression models, nor did it affect group comparisons of exposed and control subjects by $t$ test, so the sexes were analysed together. For a comparison of correlation coefficients mean values for three 30 second trials were averaged for each group.

Sway speed by tracking with the eyes open had a correlation coefficient $(r)$ with the platform of 0.588 and with the eyes closed $r$ was

Table 2 Correlation coefficient ${ }^{*}$ matrix for head tracking and force platform for speed and mean distance in 162 subjects measured simultaneously (average of three trials)

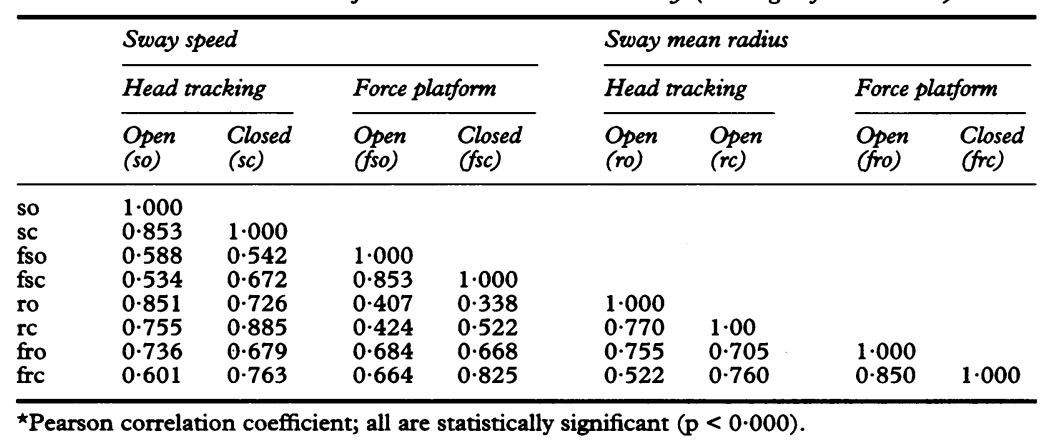

$0 \cdot 672$. Both were statistically significant $(\mathrm{p}<0.0001$; table 2$)$. For sway radius the $r$ values, both tracking and platform, were 0.755 with the eyes open and 0.760 with the eyes closed $(p<0.0001)$. Sway speed, radius, or distance on the $\mathrm{x}$ or $\mathrm{y}$ axis separately did not improve discrimination. The patterns of displacement on forward-backward (y) axis and side to side ( $x$ ) axis were similar in form for both methods in all subjects. Figure 1 (A and B) shows this similarity. Sway speed by head tracking with eyes open and with eyes closed had an $r$ value of $0.853(p<0.0001)$. The correlations for sway radius with the two devices were 0.756 with the eyes open and 0.760 with the eyes closed.

Multiple linear regression with stepwise elimination of non-significant independent variables was used to model the influence of height, weight, height $\times$ weight (interaction), age, shoe area, and grip strength on sway speed and radius. Body weight, height, and age did not contribute significantly to head tracking with the eyes open or with the eyes closed (table 3 ) but with the force platform height and weight had significant coefficients and age was marginal, which accounted for 0.2640 of the variance (adjusted $r^{2}$ ) with the eyes open and $0 \cdot 2972$ with the eyes closed. The age and weight covaried. Thus age was not a major predictor of sway speed by head tracking in these subjects between 17 and 71 years.

Linear models showed that height $\times$ weight increased head tracking sway speed and radius and accounted for more variance (adjusted $r^{2}$ ) than did height or weight alone. There was a 10 -fold to 20 -fold greater effect of height $\times$ weight on force platform speed and radius (adjusted $r^{2} 0.22$ to 0.25 ) compared with the corresponding tracking measurements (adjusted $r^{2} 0.019$ to 0.025 ). Greater grip strength decreased sway speed and radius but these coefficients, although significant, were only $10 \%$ to $20 \%$ of the coefficients of height $\times$ weight. Furthermore, grip had significant coefficients for height (adjusted $\left.r^{2} \quad 0.3749\right)$ and height $\times$ weight (adjusted $\left.r^{2} 0 \cdot 1177\right)$. Shoe area alone had a significant coefficient for sway speed and for radius but it became insignificant when the more powerful coefficient, that for height $\times$ weight, was put in the model. Sway speed with eyes open (trial 3 ) had a small significant positive coefficient with age $(r 0.007$ adjusted $\left.r^{2} 0 \cdot 1061\right)$ but with eyes closed, $r$ was smaller and not significant.

Sway speed was greater in subjects exposed to PCBs and other chemicals for four to 17 years, than for referents as measured by tracking and the platform for each trial (table 4). Speed and radius for exposed subjects were significantly different from referents by both methods for all trials ( $p$ from $<0.034$ to $<0.000$ ) and were slightly smaller for the platform. Confounding influences were minimal. More referents than exposed subjects had occupational exposures to other possible neurotoxins. ${ }^{17}$ Alcohol concentrations were not raised in any subject. Neurological dis- 

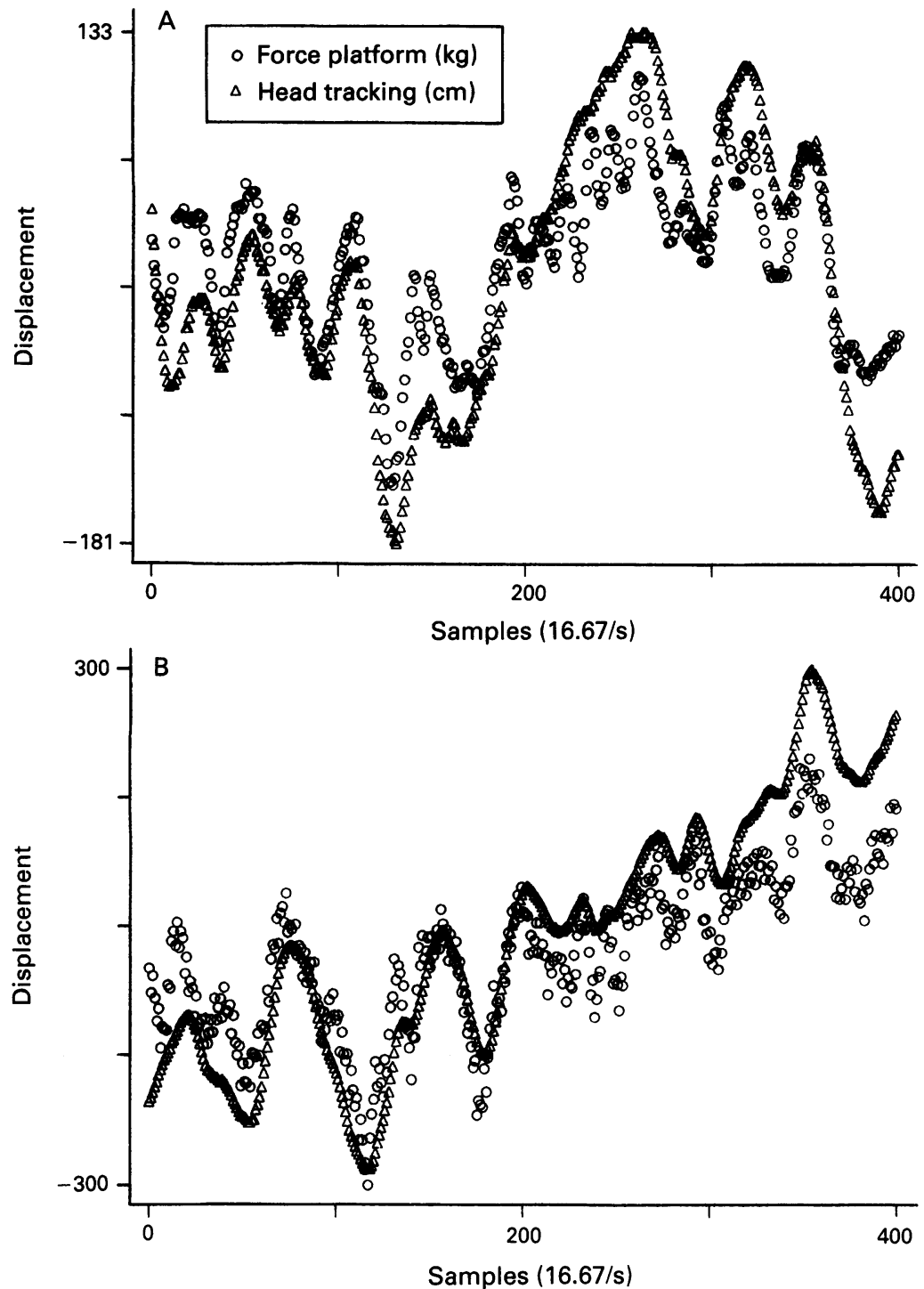

(A) Force platform and head tracking positions on $y$ axis (forward and backward) of typical unexposed subject during a 30 second trial (16.67 observation points/s (B). Force platform and head tracking positions on $x$ axis (side to side) of typical unexposed subject during a 30 second trial (16.67 observations/s.

eases were absent in both groups. The mean hours of general anaesthesia were not different between the groups and as an independent variable in regression models of sway speed or radius, total hours of anaesthesia had no significant coefficients.

Table 4 Comparison of simultaneous head tracking and force platform measurements with eyes open and closed during three 30 s trials for exposed subjects and referents

\begin{tabular}{lllll}
\hline Method & Eyes & $\begin{array}{l}\text { Referents }(n=46) \\
\text { Mean }(S D)\end{array}$ & $\begin{array}{l}\text { Exposed }(n=116) \\
\text { Mean }(S D)\end{array}$ & p Value \\
\hline Trial 1: & & & & \\
Head tracking & Open & $0.92(0.19)$ & $1.05(0.37)$ & 0.026 \\
$\quad$ Force platform & Open & $3.64(0.64)$ & $4.08(0.60)$ & 0.000 \\
Head tracking & Closed & $1.32(0.33)$ & $1.49(0.51)$ & 0.034 \\
Force platform & Closed & $4.46(1.08)$ & $5.06(1.45)$ & 0.013 \\
Trial 2 & & & & \\
Head tracking & Open & $0.90(0.21)$ & $1.05(0.39)$ & 0.013 \\
Force platform & Open & $3.53(0.64)$ & $3.98(0.62)$ & 0.000 \\
Head tracking & Closed & $1.24(0.33)$ & $1.45(0.53)$ & 0.015 \\
Force platform & Closed & $4.26(0.95)$ & $4.85(1.30)$ & 0.006 \\
& & & & \\
Trial 3: & & & & \\
Head tracking & Open & $0.92(0.25)$ & $1.08(0.40)$ & 0.014 \\
Force platform & Open & $3.53(0.50)$ & $3.97(0.55)$ & 0.000 \\
Head tracking & Closed & $1.27(0.36)$ & $1.50(0.71)$ & 0.034 \\
Force platform & Closed & $4.29(1.14)$ & $4.93(1.56)$ & 0.013 \\
\hline
\end{tabular}

Table 3 Regression models for speed of sway by head tracking with eyes open ( $\mathrm{SO}_{3}$ ) and closed $\left(\mathrm{SC}_{3}\right)$ and force platform for eyes open (FSO) and with eyes closed $\left(F S C_{3}\right)$ including grip strength and height $\times$ weight

\begin{tabular}{|c|c|c|c|c|}
\hline & Coefficient & $\begin{array}{l}\text { Standard } \\
\text { error }\end{array}$ & p Value & $\begin{array}{l}\text { Adjusted } \\
r^{2}\end{array}$ \\
\hline $\begin{array}{l}\mathrm{SO}_{3}: \\
\text { Age } \\
\text { Height } \\
\text { Weight } \\
\text { Constant }\end{array}$ & $\begin{array}{r}0.0070 \\
-0.0111 \\
0.0015 \\
1.2231\end{array}$ & $\begin{array}{l}0.0021 \\
0.0092 \\
0.0008 \\
0.5854\end{array}$ & $\begin{array}{l}0.000 \\
0.230 \\
0.071 \\
0.038\end{array}$ & $0 \cdot 1061$ \\
\hline $\begin{array}{l}\mathrm{SC}_{3}: \\
\text { Age } \\
\text { Height } \\
\text { Weight } \\
\text { Constant }\end{array}$ & $\begin{array}{r}0.0062 \\
-0.0299 \\
0.0037 \\
2.4771\end{array}$ & $\begin{array}{l}0.0036 \\
0.0161 \\
0.0014 \\
1.019\end{array}$ & $\begin{array}{l}0.085 \\
0.065 \\
0.008 \\
0.016\end{array}$ & \\
\hline $\begin{array}{l}\mathrm{FSO}_{3}: \\
\text { Age }^{\text {Height }} \\
\text { Weight } \\
\text { Constant }\end{array}$ & $\begin{array}{r}0.0066 \\
-0.0288 \\
0.0075 \\
4.1364\end{array}$ & $\begin{array}{l}0.0030 \\
0.0135 \\
0.0012 \\
0.8567\end{array}$ & $\begin{array}{l}0.031 \\
0.035 \\
0.000 \\
0.000\end{array}$ & 0.2640 \\
\hline $\begin{array}{l}\text { FSC }_{3} \text { : } \\
\text { Age } \\
\text { Height } \\
\text { Weight } \\
\text { Constant }\end{array}$ & $\begin{array}{r}0.0142 \\
-0.0767 \\
0.0202 \\
5.5928\end{array}$ & $\begin{array}{l}0.0073 \\
0.0327 \\
0.0028 \\
2.0733\end{array}$ & $\begin{array}{l}0.053 \\
0.020 \\
0.000 \\
0.008\end{array}$ & $0 \cdot 2972$ \\
\hline $\begin{array}{l}\text { SO: } \\
\text { Grip } \\
\text { Height } \times \text { Weight } \\
\text { Constant } \\
\text { Height } \times \text { Weight } \\
\text { Constant }\end{array}$ & $\begin{array}{l}-0.0072 \\
0.00003 \\
0.9210 \\
0.00002 \\
0.7837\end{array}$ & $\begin{array}{l}0 \cdot 0016 \\
8 \cdot 74 \\
0 \cdot 1054 \\
8 \cdot 69-06 \\
1 \cdot 069\end{array}$ & $\begin{array}{l}0.000 \\
0.000 \\
0.000 \\
0.025 \\
0.000\end{array}$ & $\begin{array}{l}0.1314 \\
0.0250\end{array}$ \\
\hline $\begin{array}{l}\text { SC: } \\
\text { Grip } \\
\text { Height } \times \text { Weight } \\
\text { Constant } \\
\text { Height } \times \text { Weight } \\
\text { Constant }\end{array}$ & $\begin{array}{c}-0.0102 \\
0 \cdot 00005 \\
1 \cdot 2860 \\
0.00003 \\
1 \cdot 0906\end{array}$ & $\begin{array}{l}0 \cdot 0025 \\
0.00001 \\
0 \cdot 1681 \\
0 \cdot 00001 \\
0 \cdot 1686\end{array}$ & $\begin{array}{l}0.000 \\
0.000 \\
0.000 \\
0.044 \\
0.000\end{array}$ & $\begin{array}{l}0.1053 \\
0.019\end{array}$ \\
\hline $\begin{array}{l}\text { FSO: } \\
\text { Grip } \\
\text { Height } \times \text { Weight } \\
\text { Constant } \\
\text { Height } \times \text { Weight } \\
\text { Constant }\end{array}$ & $\begin{array}{r}-0.0111 \\
0.0001 \\
2.9341 \\
0.0001 \\
2.7219\end{array}$ & $\begin{array}{l}0.0026 \\
0.00001 \\
0 \cdot 1736 \\
0 \cdot 00001 \\
0 \cdot 1750\end{array}$ & $\begin{array}{l}0.000 \\
0.000 \\
0.000 \\
0.000 \\
0.000\end{array}$ & $\begin{array}{l}0.2968 \\
0.2214\end{array}$ \\
\hline $\begin{array}{l}\text { FSC: } \\
\text { Grip } \\
\text { Height } \times \text { Weight } \\
\text { Constant } \\
\text { Height } \times \text { Weight } \\
\text { Constant }\end{array}$ & $\begin{array}{c}-0.0223 \\
0.00027 \\
2.4703 \\
0.0002 \\
2.0427\end{array}$ & $\begin{array}{l}0 \cdot 0057 \\
0.00003 \\
0 \cdot 3797 \\
0 \cdot 00003 \\
0 \cdot 3797\end{array}$ & $\begin{array}{l}0.000 \\
0.000 \\
0.000 \\
0.000 \\
0.000\end{array}$ & 0.2503 \\
\hline $\begin{array}{l}\text { Grip: } \\
\text { Height } \times \text { Weight } \\
\text { Constant }\end{array}$ & $\begin{array}{r}2 \cdot 9658 \\
54 \cdot 2865\end{array}$ & $\begin{array}{l}0.3238 \\
20 \cdot 0536\end{array}$ & $\begin{array}{l}0.000 \\
0.000\end{array}$ & 0.3749 \\
\hline $\begin{array}{l}\text { Grip: } \\
\text { Height } \times \text { Weight } \\
\text { Constant }\end{array}$ & $\begin{array}{r}0.0019 \\
19 \cdot 0286\end{array}$ & $\begin{array}{l}0.0004 \\
5.0211\end{array}$ & $\begin{array}{l}0.000 \\
0.000\end{array}$ & $0 \cdot 1177$ \\
\hline
\end{tabular}

\section{Discussion}

Sway speed and distance (mean radius) were easily measured simultaneously by head tracking and the force platform in 46 reference subjects and 116 chemically exposed subjects. The important finding is that they were equivalent methods to measure balance. The fidelity of the head tracking device equals that of the platform at the working frequencies. Neither signal required filtering. There was no evidence of effects of head movement independent of movements of the trunk while subjects stood still. Head tracking is effectively independent of body size (height $\times$ weight) but otherwise balance was measured equally well by either method. Both devices are portable but the head tracking instrument is lightweight and more easily carried and set up. The platform requires no headband so may be accepted slightly better by subjects. The force platform is much more sensitive to body size expressed as height $x$ weight and to 
weight alone than is head tracking. Although this sensitivity would be of no consequence in comparing populations with the same weight distributions, it may be important for groups that differ and could bias results in longitudinal studies when weights of people vary. Grip strength was negatively correlated with sway speed and radius but this may be an artifact, as exposed women had significantly less grip strength than referents.

Force platforms are influenced materially by body size. 151819 The head tracking method's independence of body size or weight may be an advantage, especially when a group's weights are not equally distributed or changed during the study. Age did not have a significant coefficient for balance in ambulatory subjects from ages 17 to 71 , although it has been shown that balance deteriorates beyond 80 years of age. ${ }^{114}$ Other variables such as overall distance, $x$ and $y$ axis distances, and acceleration can be derived from the multisample per second recordings of either head tracking or the force platform. These had no advantages in our comparisons.

During the past decade force platforms have been preferred with body (belt line) magnetic tracking used occasionally. ${ }^{6}$ Because none of the current devices is lightweight and easily adaptable for field studies we have shown that a head tracking device that is easily portable produces similar data. Both devices showed significant impairment of balance in a population exposed to PCBs, dibenzofurans, TCE, and other solvents, which also showed other neurophysiological and neuropsychological abnormalities. ${ }^{17}$

The chemically exposed group had abnormally greater sway speeds and radii than referents, which were associated with four to 17 years of exposures to PCBs, dibenzofurans, and solvents including TCE from well water. Also, the metal casting operation may have added some airborne chemical exposure particularly to TCE. Presumably tricyclic polychlorinated aromatic compounds, including dibenzofurans and dibenzo-p-dioxins, contaminated the commercial grade PCBs and were transformed from PCBs as temperatures in metal casting reached the $270-620^{\circ} \mathrm{C}$ needed to create these products in the laboratory..$^{20}$ Also, these compounds have been found after fires of transformers containing PCBs. ${ }^{22}$ Firefighters exposed to thermal transformation products of PCBs, who were studied in 1988, had abnormal sway radius and speed with the eyes open ${ }^{23}$ and, when com- pared with recent referent subjects, abnormal sway speed with the eyes closed as well. The present paper confirms previous findings of abnormal balance in subjects exposed to PCBs using two sensitive devices. These new findings supplement the evidence for reduced peripheral sensory and motor function and nerve conduction velocity. ${ }^{12}$

1 Chen RC, Tang SY, Miyata H, et al. Polychlorinated biphenyl poisoning: correlation of sensory and motor nerve conduction, neurologic symptoms and blood levels of polychlorinated biphenyls, quaterphenyls and diben-

2 Murai Y, Kuroiwa Y. Peripheral neuropathy in chlorobiphenyl poisoning. Neurology 1971;21:1173-6.

3 Rogan WI, Gladen BC. Neurotoxicology of PCBs and related compounds. Neurotoxicology 1992;13:27-36.

4 Romberg MH. Lehrbuch der Nervenkrankheiten des menschen. 2nd. Berlin: A Hirschward, 1851

5 Bhattacharya A, Morgan R, Shukla R, Ramakrishanan $H K$, Wang $L$. Non-invasive estimation of afferent inputs for postural stability under low levels of alcohol. $A n n$ Biomed Eng 1987;15:533-50.

6 Dean EM, Griffiths CJ, Murray A. Stability of the human body investigated by sway magnetometry. $f$ Med Eng Technol 1986;10:126-30.

7 Edwards AS. Body sway and vision. $f$ Exp Psychol Gen 1946;36:526-35.

8 Glorig A, Davis H. Age, noise and hearing loss. Ann Otol Rhinol Laryngol 1961;70:556-71.

9 Jansen EC, Larsen RE, Olesen MB. Quantitative Romberg's test. Acta Neurol Scand 1982;66:93-9.

10 Savolainen $\mathrm{K}$. Combined effects of xylene and alcohol on the central nervous system. Acta Pharmacologica et Toxicologica 1980;46:366-72.

11 Sheldon JH. The effect of age on the control of sway. Gerontology 1963;5:129-38.

12 Thyssen HH, Brynskov J, Jansen EC, Munster-Swendsen $\mathrm{J}$. Normal ranges and reproducibility for the quantitative Romberg's test. Acta Neurol Scand 1982;66:100-4.

13 Goldberg L. Quantitative studies on alcohol tolerance in man. Acta Physiol Scand 1943;5:28-55.

14 Bormann $\mathrm{K}$, Jalavisto E. Standing steadiness in old and young persons. Am Med Exp Biol Fem 1953;31:446-55.

15 Dick RB, Bhattacharya A, Shukla R. Use of a computerized postural sway measurement system for neurobehavioral toxicology. Neurotoxicol Teratol 1990;12:1-6.

16 Kilburn KH, Warshaw RH, Hanscom B. Are hearing loss and balance dysfunction linked in construction iron workers? Br f Ind Med 1992;49:138-41.

17 Kilburn KH, Warshaw RH. Neurobehavioral testing of subjects exposed residentially to ground water contaminated from an aluminum die casting plant and local referents. F Toxicol Environ Health 1993;39:101-14.

18 Goldie PA, Bach TM, Evans OM. Force platform measures for evaluating postural control: reliability and sures for evaluating postural control: reliab.
validity. Arch Phys Med Rehabil 1989;70:510-7.

19 Murray MP, Seireg AA, Sepic SB. Normal postural stability and steadiness: quantitative assessment. $\mathcal{f}$ Bone foin Surg (Am) 1975;57:510-6.

20 Buser HR. Formation, occurrence and analysis of polychlorinated dibenzofurans, dioxins and related compounds. Environ Health Perspect 1985;60:259-67.

21 Hutzinger Choudhry GG, Chittim GB, Jonston LE. Formation of polychlorinated dibenzofurans and dioxins during combustion, electrical equipment fires and PCB incineration. Environ Health Perspect 1985;60:3-9.

22 Fitzgerald EF, Stanafast SI, Youngblood LG, Melius JM Janerich DT. Assessing the health effects of potential exposure to PCBs, dioxins and furans from electrical transformer fires: The Binghamton state office building transformer fires: The Binghamton state office building medical surveillance

23 Kilburn KH, Warshaw RH, Shields MG. Neurobehavioral dysfunction in firemen exposed to polychlorinated biphenyls (PCBs): possible improvement after detoxification. Arch Environ Health 1989;44:345-50. 